\title{
Desenvolvimento Sustentável: limites e perspectivas no debate contemporâneo
} Sustainability development: limits and perspectives in the contemporary debate Développement Soutenable : limites et perspectives dan le débat contemporain Desarrollo Sostenible: límites y perspectivas en el debate contemporáneo

\author{
Maria do Perpétuo Socorro Rodrigues Chaves* \\ Débora Cristina Bandeira Rodrigues
}

Recebido em 3/2/2006; revisado e aprovado em 20/6/2006; aceito em 2/8/2006

\begin{abstract}
Resumo: O presente artigo traz para discussão reflexões em torno das concepções de desenvolvimento sustentável existentes na contemporaneidade, abordando os limites e perspectivas que envolvem a concretização desta forma de desenvolvimento. A presente discussão se faz pertinente à medida que, entende-se que uma proposta viável de desenvolvimento sustentável coloca em evidência aspectos para construção de novos rumos no tratamento das questões ambientais planetárias, ao mesmo tempo em que aponta para as determinações políticas e econômicas que embasam o modelo de desenvolvimento vigente.
\end{abstract}

Palavras-chave: Desenvolvimento sustentável; meio ambiente; política.

Abstract: The present article brings to discussion reflections around the conceptions of maintainable development existent actually, approaching the limits and perspectives which involve the materialization of this development way. The present discussion is done pertinent as well as understands each other a viable proposal of maintainable development places in evidence aspects for construction of new directions in the treatment of the planetary environmental subjects, at the same time in that appears for the political and economical determinations that base the model of effective development.

Key words: Maintainable development; environment; politics.

Résumé: Le présent article mène à discuter sur des réflexions autour des concepts du développement durable de l'environnement existant, en abordant les limites et perspectives qui englobent la concrétisation de cette forme de développement. Cette discussion se fait pertinente à mesure que la compréhension montre l'existence d'une proposition valable de développement durable et met en évidence des aspects pour obtenir de nouvelles manières de traitement des milieux environnants planétaires, en même temps qu' elle indique les déterminations politiques et économiques qui forment la base effective du modèle actuel de développement

Mots-clé: Développement; milieu environnant; politique.

Resumen: El presente artículo trae para discutir reflexiones en torno a las concepciones de desarrollo sustentable existentes en la contemporaneidad, abordando los límites y perspectivas que envuelven la concretización de esta forma de desarrollo. La presente discusión se hace pertinente en la medida que, se entiende que una propuesta viable de desarrollo sustentable coloca en evidencia aspectos para construcción de nuevos rumbos en el tratamiento de las cuestiones ambientales planetarias, al mismo tiempo en que apunta para las determinaciones políticas y económicas que envasan el modelo de desarrollo vigente.

Palabras clave: Desarrollo sustentable; medio ambiente; política.

Tão ambígua quanto usual, a expressão "desenvolvimento sustentável" remete a uma corrente de reflexões que perdura há mais de vinte anos (GODARD, 1997, p.107).

\section{Introdução}

Nas últimas três décadas a discussão em torno da relação Estado-sociedade-natureza tem sido intensificada, tanto em níveis internacionais quanto nacionais, podendo ser identificados neste processo diferentes tendências de análise e interpretação, entre elas encontra-se a proposta de desenvolvimento sustentável.

Segundo Godard (2002), foi após a década de 70 que começa a se estabelecer a consciência de que as raízes dos problemas ambientais estariam nas formas de desenvolvimento tecnológico e econômico, sendo impossível o tratamento das questões, sem uma reflexão e conseqüente ação sobre este modelo de desenvolvimento proposto. Assim, as chamadas políticas de meio ambiente não podem ser tratadas "à margem dos proces-

\footnotetext{
* Docente do Dep. Serviço Social da Universidade Federal do Amazonas, Doutora em Política Científica e Tecnológica; Coordenadora do Grupo Interdisciplinar de Estudos Sócio-ambientais e de Desenvolvimento de Tecnologias Apropriadas na Amazônia. (socorro.chaves@ig.com.br).

** Pesquisadora Grupo Interdisciplinar de Estudos Sócio-ambientais e de Desenvolvimento de Tecnologias Apropriadas na Amazônia; Mestre em Sociedade e Cultura na Amazônia; Doutoranda em Biotecnologia. (deb.crist@ig.com.br).
} 
sos de ação coletiva e de organização econômica" (p.201). Pode-se afirmar que estas são a base das referências feitas usualmente às noções de ecodesenvolvimento (SACHS, 1980) ou de desenvolvimento sustentável (GODARD, 1994).

A noção de desenvolvimento sustentável, segundo alguns autores (GODARD, 2002, IGNACY, 2002 e SIMONIAN, 2000) ainda é incerta, uma vez que esta se encontra segundo Godard (1997) no cruzamento de várias tradições intelectuais, onde na atualidade serve para expressar um desejo de "conciliação entre desenvolvimento econômico e a proteção ao meio ambiente do planeta a longo prazo" (p.108), ao mesmo tempo em que favorece aproximações intelectuais, recomposições teóricas e reorganizações institucionais. $\mathrm{O}$ autor chama atenção para o fato de que, estas noções mais abrem campos novos de debate que propriamente organizam as noções já existentes. Ressalta ainda, que os "conceitos e doutrinas, regras e procedimentos práticos vão ser elaborados de acordo com a conveniência das decisões econômicas, das regras jurídicas e das inovações institucionais" (p.109).

Neste sentido, o significado das questões em jogo devem ser buscados, por um lado nas concepções teóricas e por outro nas funções exercidas nos processos políticos e institucionais. Neste contexto, pode-se afirma que nas sociedades contemporâneas o desenvolvimento assume valor central, sendo este valor alimentado por vários componentes ideológicos: necessidade de progresso técnico identificado ao progresso humano, ambição de domínio sobre a natureza (GODARD, 2002).

Nesta perspectiva, pretendemos discutir, ainda que de forma pré-liminar, as noções que envolvem a proposta de um desenvolvimento sustentável, sem perder de vista os limites e possibilidades que envolvem esta questão.

\section{Noção de Desenvolvimento}

\section{Sustentável: uma construção a partir de multiplas origens}

O conceito de desenvolvimento sustentável... É um enfoque de desenvolvimento sócioeconômicos orientado para: a satisfação de necessidades básicas; o reconhecimento do papel fundamental que a autonomia cultural desempenha nesse processos de mudança; oferecer um conjunto de critérios para se avaliar a pertinência de ações mais especificas (SACHS, Inagcy).

$\mathrm{O}$ aprofundamento e visibilidade nos debates em torno de uma proposta de desenvolvimento sustentável, segundo Godard (1997), não tem sua origem no relatório de Brundtland, mesmo reconhecendo sua contribuição, o referido autor aponta três principais correntes teóricas nos meios científicos e dos especialistas vinculados na análise do desenvolvimento econômico e de suas conseqüências sobre o meio ambiente.

No começo dos anos 70, sob a direção do Programa das Nações Unidas para o Meio Ambiente, encontra-se uma primeira corrente de pensamento (FARVAR, 1977; GLAESER, 1984; SACHS e SIMONIS, 1990) que se dedica em promover o que ficou conhecido como "estratégias de ecodesenvolvimento" (SACHS, 1974, 1980 e 1993). Esta seria concebida como uma nova abordagem do desenvolvimento, onde as estratégias pensadas teriam suas bases fundadas no "atendimento às necessidades fundamentais (habitação, alimentação, meios energéticos de preparação de alimentos, água, condições sanitárias, saúde e decisões nas participações) das populações menos favorecidas, prioritariamente nos países em desenvolvimento, na adaptação das tecnologias e dos modos de vida às potencialidades e dificuldades específicas de cada ecozona, na valorização dos resíduos e na organização da exploração dos recursos renováveis pela concepção de sistemas cíclicos de produção, sistematizando os ciclos ecológicos" (GODARD, 1997, p.111).

Esta perspectiva de abordagem em primeiro plano focaliza às populações, a partir da percepção de que as formas de subsistência desenvolvidas, bem como as atividades, têm sua organização fora da economia de mercado oficial (agricultura familiar de subsistência, economia urbana informal), baseado neste entendimento as bases do desenvolvimento destas atividades estariam na participação direta das populações envolvidas no processo, ao mesmo tempo em que buscam a criação de novas formas institucionais de impulso e de planificação em nível dos estabelecimentos humanos e distritos rurais.

Nesta forma de abordagem, considerada crítica e pragmática quanto a forma de 
desenvolvimento dominante proposto no pós-guerra, sua concretização se deu por meio de projetos, de níveis experimentais ou demonstrativos, buscando apóio em iniciativas de organizações populares locais, de militantes ou independentes, com apoio de organizações internacionais ou de agências públicas. Encontra limitações no aspecto econômico e político, tendo em vista sua proposta, que apresentava como necessidade para se discutir o ecodesenvolvimento, a necessidade de mudanças políticas nacionais e uma reestruturação das relações econômicas Norte-Sul. Isto significaria uma mudança de postura nos modos de vida e desenvolvimento dos países industriais, sendo esta considerada condição sine qua non para uma harmonização dos direitos ao desenvolvimento, não só de alguns países mas de todos, bem como a preservação do meio ambiente do planeta. Esta proposta considerada radical, não agradou a muitos, o que levou, após um entusiasmo inicial, a proposta de ecodesenvolvimento a ficar relegada às esferas marginais.

Numa segunda corrente de pensamento (CONSTANZA, 1989; DALY, 1977; GEORGESCU-ROEGEN, 1978 e PASSET, 1979), tem-se a proposta de um projeto que desenvolva uma nova representação teórica da atividade econômica tendo como ponto de partida a confrontação com os novos conceitos e modelos desenvolvidos pelas ciências da natureza, como: termodinâmica, evolução e organização do ser vivente, ecologia, entre outros. Os teóricos ligados a esta corrente de pensamento iniciam com formulações críticas, tais como: questionam a autogestão do sistema econômico, impossibilidades da extrapolação das soluções locais para globais, impossibilidades de reciclagem completa das matérias-primas, devido aos fenômenos da entropia, não possibilidade de troca entre capital natural e capital produtivo reprodutivo. Os resultados destas abordagem conduz ao que se pode chamar de " bioeconomia" ou "economia ecológica" (ecological economics), onde segundo autor, a inspiração interdisciplinar permanece muito variada.

A terceira forma de abordagem apresentada pelo autor, se coloca no prolongamento da teoria neoclássica do equilíbrio e do crescimento econômico. Para alguns au- tores não existe relação entre crescimento e degradação do meio ambiente (BECKMAN, 1974), apresentam aqui um erro de objetivo, uma vez que "a teoria do crescimento é organizada em torno da questão da poupança e do investimento, ou seja, do julgamento dos fluxos de consumo no tempo" (GODARD, 1997, p.113), ao contrário os problemas ambientais deveriam ser tratados como ineficácia da distribuição dos bens econômicos em dado momento. Foram feitas análises sobre os regimes de exploração de recursos naturais não renováveis (DASGUPTA e HEAL, 1979 e SOLOW, 1974) ou renováveis (CLARK, 1973 e 1990) com objetivo de identificar: a) as condições possíveis de uma exploração economicamente ideal; b) verificar as implicações sobre a evolução destes recursos; e c) deduzir as possíveis conseqüências analíticas para o estudo do crescimento e da distribuição do bem estar. Neste processo vários modelos foram construídos a fim de analisar as implicações lógicas de uma exigência de equidade entre as gerações nas trajetórias de crescimento máximo, os respectivos níveis de consumo acessíveis a cada geração, bem como as condições de transferência de custos de uma geração a outra.

As correntes apresentadas são debatidas a fim de dar um conteúdo ao objetivo de desenvolvimento sustentável. Contudo, a definição mais conhecida e citada é a do relatório Brundtland (1988), onde desenvolvimento sustentável "é o que responde às necessidades do presente sem comprometer a capacidade das gerações futuras de responder às suas próprias necessidade" (GODARD, 1997, p.113). Autor ressalta que, ainda assim, são várias as formas de interpretação desta definição.

Neste sentido, entende-se que há limites e possibilidades apontados nas diferentes perspectivas de desenvolvimento sustentável.

\section{Limites e perspectivas para uma nova proposta de desenvolvimento sustentável}

As diferentes noções de sustentabilidade ou mesmo de desenvolvimento, dificultam a realização de uma interpretação prática dos objetivos políticos formulados em 
torno da proposta de "desenvolvimento sustentável". Segundo Godard (1997), os conhecimentos produzidos em torno desta temática apresentam limitações, são incompletos e controvertidos. Alerta para não garantia de transferências ou mesmo a tradução de raciocínios de determinada escala de organização ou de uma área de conhecimento para outra. È importante ressaltar que, as diferentes definições apresentadas apontam para exigência de sustentabilidade como valor normativo, e que permita formulação de objetivos coletivos, aspecto que tem sido alcançado ao nível do planeta. O desafio se impõe na passagem destas normas a nível planetário para regras ou normas válidas em escalas locais, onde são vários os mecanismos que podem interferir no processo. A exigência de sustentabilidade não torna homogênea as diferentes realidades sócio-econômica e culturais que constituem o planeta.

Desta forma pode-se dizer que a sustentabilidade deverá ter diferentes estruturas a partir das diferentes escalas de organização na qual se encontre inserida. Uma principal dificuldade para concretização desta proposta é que do ponto de vista dos fenômenos ecológicos, são analisados primeiramente em nível local (ecossistemas) ou regional (biomassa e regiões biogeográficas), e depois, de forma mais abrangente e conjuntural a nível planetário.

Com as discussões desenvolvidas e a partir das análises realizadas, o que se pode perceber é que "aplicação de uma política de sustentabilidade do desenvolvimento não pode ser derivada diretamente nem de uma otimização econômica intertemporal, observados pelos preços nos mercados, nem dos conhecimentos científicos dos processos biofísicos, dos quais depende a reprodução de nosso meio ambiente" (GODARD, 1997, p.117). Neste caso, a operacionalização de uma proposta de desenvolvimento sustentável, deve tomar como referência à construção de mediação de critérios estratégicos que possam dar conta do atual estado de incertezas que envolvem esta questão. Tais critérios deverão orientar a gestão dos elementos passiveis de conhecimento no momento atual.

Referido autor cita três exemplos de atitudes que podem dar base para uma política de "desenvolvimento sustentável", que podem ser relacionados como: 1) um comportamento de segurança e de prevenção dos riscos conhecidos; 2) a otimização do tempo para conhecer os fenômenos, e assim responder de forma mais eficaz aos problemas ainda incertos neste campo; busca por soluções "de menor arrependimento", que possam atender de forma simultânea vários objetivos da coletividade (HOURCADE, 1994 apud GODARD 1997). Contudo, vemos hoje um princípio que pode ter influência ainda maior que o "desenvolvimento sustentável", que é o "princípio da precaução". Este princípio tem suas bases estabelecidas no direito internacional, posteriormente entrando no direito interno, aonde vai além das questões ambientais e passa a tingir o conjunto dos riscos maiores, principalmente no campo da saúde.

Pelo "princípio da precaução" entende-se "que ele pode exigir ações que limitem as emissões de certas substâncias potencialmente perigosas, sem esperar que uma relação de causalidade seja estabelecida de maneira formal sobre bases científicas" (p.118).

Neste campo do debate é possível estabelecer uma dupla relação entre as noções de desenvolvimento sustentável e o princípio da precaução: 1) ambas tem sua gênese na tomada de consciência de que determinadas conseqüências ou ações são irreversíveis; 2) na área do desenvolvimento sustentável, com tantas incertezas, pode-se aproximar estas noções de duas maneiras: a concretização de uma política de desenvolvimento sustentável, hoje significaria assumir uma postura de precaução diante dos riscos cujas conseqüências seriam sofridas pelas gerações futuras; ao contrário disso, este mesmo princípio possibilitaria dar uma tradução prática a algumas preocupações que não poderiam transformar-se em ação, cita o exemplo do risco climático do planeta.

$\mathrm{Na}$ linha do desenvolvimento sustentável existem aqueles que acreditam que a medida da precaução deve ser bem avaliada, medida, para outros a medida deveria ser imposta de forma absoluta. Existem ainda, os que impõem a necessidade de resultados de pesquisa que demonstrem as conseqüências de determinados projetos antes mesmo de serem autorizados e implementados. 
A discussão, em torno deste princípio, demonstra a relação ambivalente entre decisão e conhecimento científico. Vários questionamentos são levantados, a partir deste debate, quanto a responsabilidade da prova exigida para que determinadas ações sejam desenvolvidas, num cenário de incertezas e onde os saberes ainda não estão estabilizados, neste caso, de quem é a responsabilidade da prova? E qual a prova a ser dada?

Uma evidência que se coloca hoje nos fóruns de discussão é que, a partir do momento em que se estabeleceu o princípio da precaução nos tratados e convenções, os Estados assumiram a não preocupação nos momentos das tomadas de decisões sobre questões que hoje são colocadas em discussão, como exemplo temos a mudança climática do planeta, mesmo na ausência de prova científica teórica e empírica.

Autor coloca que este princípio da precaução pode ajuda no processo de modificação dos comportamentos, mas chama atenção para o fato de também servir de inibidor para o desenvolvimento das empresas e da tecnologia. Neste ponto, poderia se tornar contraditória com a proposta do desenvolvimento sustentável. Para efetivação deste princípio, são necessários estabelecimentos de regras que possam garantir uma aplicação sensata e previsível. O que se constitui em desafio a ser superado.

\section{Funções e objetivos do desenvolvimento sustentável na contemporâneidade}

A noção de "desenvolvimento sustentável" tem adquirido difusão ampla e diversificada no meio social e acadêmico, o que implica na possibilidade de atendimento de uma variedade de projetos, valores, atores e grupos sociais os mais diversos. Contudo, as incertezas que ainda envolvem esta noção colocam à função que tem exercido na atualidade, entendida num processo de construção buscando: aproximar problemáticas e interesses diferentes, abrindo caminho para novas formas de relação, favorecendo ainda reorganizações.

Numa perspectiva prática de abordagem, a noção de desenvolvimento sustentável atende de forma indiscutível a vários objetivos: o primeiro apresenta a necessidade de se favorecer a eliminação das barreiras entre diferentes disciplinas e diferentes tradições de pensamento, buscando assim, a construção da interdisciplinaridade, que ainda se articula com certa dificuldade, tendo em vista os muros construídos pelo próprio conhecimento científico.

Para Leff (2002), a superação do padrão de conhecimento fragmentado dominante, vai depender da nossa capacidade de perceber e discutir a problemática em toda sua complexidade e totalidade, não centrando as análises na separação, mas buscando a construção de enfoques mais integrados e democráticos de percepção das questões ambientais. Neste sentido, a proposta de desenvolvimento sustentável, pode proporcionar certo equilíbrio entre as diferentes disciplinas científicas advindas de diferentes tradições de pensamento, estabelecendo uma interlocução fecunda entre estas. Faz-se necessário, ainda, o reconhecimento da relevância das discussões éticas e morais, do estabelecimento de ligações entre as ciências da natureza no interior das análises econômicas, procurando, ainda, articular os dados científicos e os "procedimentos de revelação dos valores coletivos, no interior dos dispositivos de gestão" (GODARD, 1997, p.123); o segundo objetivo proposto, seria o de reintegrar as políticas de meio ambiente numa perspectiva de desenvolvimento econômico, este aspecto vem confirmar um consenso político internacional de manter o desenvolvimento econômico no centro das decisões e da sociedade, indo de encontro a toda decisão pautada na conservação da natureza. Segundo Godard (2002), umas das questões centrais que emergem no contexto internacional pós década de 70, é a discussão quanto ao grau de compatibilidade entre o desenvolvimento econômico e a preservação do meio ambiente. A partir desta perspectiva de análise, se teria uma tese de incompatibilidade entre estes dois objetivos, o que implica idéia da necessidade de um "crescimento zero" ou mesmo de uma situação "estacionária" (DALY, 1997), podendo ter ainda uma redução no crescimento (GEORGESCU-ROEGEN, 1979).

Nesta linha de pensamento, opõem-se duas antíteses: para determinado grupo, somente com taxa elevada de crescimento se 
poderia ter o financiamento de uma política ambiental vigorosa, centrada na difusão rápida da inovação, considerando custos de manutenção ou de restauração de ambientes, bem como para concretização de mecanismos de reciclagem de materiais ou de eliminação de dejetos; para outro grupo, seria possível pensar harmonização entre os objetivos do desenvolvimento e a preservação ambiental, mas assumir tal postura exigiria a elaboração de uma nova concepção de modelos de desenvolvimento, o que implicaria mudanças significativas nos modos de vida, nos modos de produção, assim como nas opções técnicas e nas formas de organização social e das relações internacionais.

Esta perspectiva de análise revela o quanto à relação sociedade e natureza são resultado de uma construção históricosocial, a partir do estabelecimento das relações dos homens entre si, num determinado tipo de sociedade. Este modelo precisa ser repensado, uma vez que as políticas de meio ambiente não podem ser mais marginalizadas ou relegadas a um plano secundário as decisões econômicas e sociais. Neste sentido, os princípios estabelecidos na Declaração do Rio de Janeiro sobre "meio ambiente e desenvolvimento" expressam, principalmente nos princípios 4 e 8 que "para chegar a um desenvolvimento sustentável, a proteção do meio ambiente deve fazer parte integrante do processo de desenvolvimento e não pode ser considerada isoladamente; e o segundo estabelece que a fim de chegar a um desenvolvimento sustentável e a uma melhor qualidade de vida para todos os povos, os Estados deveriam reduzir e eliminar os modos de produção e de consumo não viáveis, e promover políticas demográficas apropriadas" (p.124).

Por fim, um terceiro objetivo apresentado coloca a necessidade de ligar a problemática de meio ambiente e relações NorteSul, para efetivação deste objetivo se faz necessário num primeiro momento o estabelecimento de um compromisso, uma vez que os países do sul defendem seus interesses de desenvolvimento econômico e de privilégios quanto ao acesso a financiamentos e tecnologias. Neste contexto, os países do Norte se apresentam de forma mais sensível às questões de preservação e equilíbrio do meio ambiente. De maneira mais aprofundada, as questões pertinentes ao futuro do meio ambiente "depende da evolução do conteúdo global dos modos de desenvolvimento no Norte como no Sul (modos de consumo, escolha de tecnologias, organização do espaço, gestão dos recursos e dos resíduos)" (GODARD, 1997, p.125), e estas decisões não dependem única e exclusivamente dos setores especializados da ação pública, mas dizem respeito ao conjunto da sociedade. Algumas ações desenvolvidas nas últimas décadas demonstram certa mudança de atitude frente às questões do meio ambiente, uma delas foi a convenção internacional sobre o clima e a biodiversidade, realizada e assinada no Rio de Janeiro em junho de 1992, onde para além dos conflitos de prioridades entre Norte e Sul, se estabeleceram compromissos.

Neste contexto, a retórica do desenvolvimento sustentável tem sido utilizada por diferentes grupos como recurso de denúncia política ou exercício de cidadania. Este aspecto revela que, o tratamento desta temática tem possibilitado abertura de novos espaços de expressão, ao mesmo tempo em que se constitui como novo espaço de legitimidade internacional.

\section{Considerações}

As discussões em torno de uma proposta viável de desenvolvimento sustentável colocam em evidência aspectos que precisam ser tratados, de forma a poder se estabelecer novos rumos para o tratamento das questões ambientais planetárias, ao mesmo tempo em que aponta para as determinações políticas e econômicas que embasam o modelo de desenvolvimento vigente.

Neste cenário algumas questões, segundo Sachs (2002) se impõe: como promover um desenvolvimento sócio-econômico, capaz de trabalhar a partir de princípios éticos que respeitem, as gerações presentes sem comprometer as gerações futuras? Como estabelecer, neste modelo de sociedade, uma relação com a natureza que não referende a consolidação de práticas predatórias comumente efetivadas? Como estabelecer um novo padrão social de comportamento, não de dominação do homem sobre a natureza, mas trabalhando no estabelecimento de uma simbiose sociedade-natureza? 
Considerando estes questionamentos, para o referido autor, o conceito de sustentabilidade não se constitui algo estático, mas dinâmico, uma vez que busca levar em consideração as crescentes necessidades das populações, assim "O desenvolvimento sustentável não representa um estado estático de harmonia, mas, antes, um processo de mudança, no qual a exploração dos recursos, a dinâmica dos investimentos, e a orientação das inovações tecnológicas e institucionais são feitas de forma consciente face às necessidades tanto atuais quanto futuras" (SVEDIN, 1987 apud SACHS, 2002, p.474).

Para Sachs (2002), a partir desta perspectiva de interpretação, o conceito de sustentabilidade apresenta cinco dimensões principais:

a. "Sustentabilidade social", aspecto que deve ter como base o estabelecimento de uma proposta de desenvolvimento que assegure um crescimento estável, com distribuição eqüitativa de renda, garantindo o direito de melhoria de vida das grandes massas da população.

b. "Sustentabilidade econômica", possível a partir de um fluxo constante de inversões públicas e privadas, além do manejo e alocação eficiente dos recursos naturais.

c. "Sustentabilidade ecológica", através da expansão da capacidade de utilização dos recursos naturais disponíveis no planeta terra, com menor nível de impacto ao meio ambiente. Impondo-se, ainda, a necessidade de redução do volume de substâncias poluentes, a partir da adoção de políticas de conservação de energia e de recursos, entre outras medidas.

d. "Sustentabilidade geográfica", uma vez que a maioria dos problemas ambientais tem sua origem na distribuição espacial desequilibrada dos assentamentos humanos e das atividades econômicas. Dois exemplos citados, para ilustrar tal questão, é a excessiva concentração da população em áreas metropolitanas, e a destruição de ecossistemas frágeis, de fundamental importância, pela falta de controle nos processos de colonização. Estes exemplos revelam a necessidade de se buscar uma nova configuração para questão rural-urbano de forma mais equilibrada.

e. "Sustentabilidade cultural", esta se apresenta de forma mais complexa para efetivação, uma vez que exigiria pensar o processo de modernização de forma endógena, trabalhando as mudanças de forma sintonizada com a questão cultural vivida em cada contexto específico. Deste princípio, emerge a hipótese de um acesso a modernidade a partir de múltiplas vias de acesso, onde segundo Touraine (1988), "além da necessidade de se traduzir o conceito normativo de desenvolvimento sustentável numa pluralidade de soluções locais, adaptadas a cada ecossistema, a cada cultura e, inclusive, soluções sistêmicas de âmbito local, utilizando-se o ecossistema como um paradigma dos sistemas de produção elaborados pelo homem..." (apud SACHS, p.475).

Observando estas dimensões, o conceito de desenvolvimento sustentável ora em discussão revela os limites e fragilidades dos aspectos ecológicos globais, onde o enfoque de desenvolvimento sócio-econômico tem sua orientação voltada para satisfação das necessidades básicas para grande massa da população que vive em situação de risco e exclusão social, reconhecendo ao mesmo tempo o papel fundamental que o respeito à diversidade sociocultural desempenha neste processo.

Nesta linha de análise, Chaves (2004) afirma que a proposta de desenvolvimento sustentável abrange, ao mesmo tempo, aspectos econômicos, sociais, culturais, políticos, tecnológicos e ecológicos, buscando uma integração entre estes vários fatores.

$\mathrm{O}$ que se pode perceber diante de todas as abordagens quanto à noção, conceituação de desenvolvimento sustentável, o que se coloca em evidência é um processo de construção, onde as várias correntes de pensamento do conhecimento científico estão sendo convocadas para discutir e estabelecer critérios, que orientem as ações de desenvolvimento social e econômico numa perspectiva de simbiose com a natureza. 


\section{Referências}

CHAVES, Maria do P. Socorro R. Desenvolvimento sustentável. Manaus: UFAM, junho de 2004. Aula expositiva no Doutorado em Biotecnologia.

GODARD, Olivier. O desenvolvimento sustentável: paisagem intelectual. In: CASTRO, Edna; PINTON, Florence (Orgs.). Faces do trópico úmido - conceitos e questões sobre desenvolvimento e meio ambiente. Belém: Cejup/UFPA-NAEA, 1997.

. A gestão integrada dos recursos naturais e do meio ambiente: conceitos, instituições e desafios de legitimação. In: VIEIRA, Paulo Freire; WEBER, Jacques (Orgs.). Gestão de Recursos Naturais Renováveis e
Desenvolvimento - novos desafios para a pesquisa ambiental. 3.ed. São Paulo: Cortez, 2002.

IGNACY, Sachs. Desenvolvimento sustentável, bioindustrialização descentralizada e novas configurações rural-urbanas: os casos da Índia e do Brasil. In: VIEIRA, Paulo Freire; WEBER, Jacques (Orgs.). Gestão de Recursos Naturais Renováveis e Desenvolvimento - novos desafios para a pesquisa ambiental. 3.ed. São Paulo: Cortez, 2002.

SIMONIAN, Ligia T. L. Políticas públicas, desenvolvimento sustentável e recursos naturais em áreas de reserva na Amazônia brasileira. In: Coelho, Maria C. Nunes, Ligia Simonian, Nobert Fenzl (Orgs). Estado e Políticas públicas na Amazônia: Gestão de recursos naturais. Belém: CEJUP/UFPA-NAEA, 2000. 